\title{
The Influencing Mechanism of
}

\section{Three-Dimensional Capital on the Employment of Land-Expropriated Farmers}

\section{-Based on Structural Equation Model}

\author{
Hui Jia, Qiujin Zhao, Xuxia Tian, Yufei Hu \\ School of Economics and Management, Beijing Institute of Petrochemical Technology, Beijing, China \\ Email: jiahui@bipt.edu.cn
}

How to cite this paper: Jia, H., Zhao, Q.J., Tian, X.X. and Hu, Y.F. (2019) The Influencing Mechanism of Three-Dimensional Capital on the Employment of Land-Expropriated Farmers-Based on Structural Equation Model. Journal of Service Science and Management, 12, 665-681.

https://doi.org/10.4236/jssm.2019.125046

Received: July 19, 2019

Accepted: August 23, 2019

Published: August 26, 2019

Copyright ( 2019 by author(s) and Scientific Research Publishing Inc. This work is licensed under the Creative Commons Attribution International License (CC BY 4.0).

http://creativecommons.org/licenses/by/4.0/

\begin{abstract}
Land-expropriated farmers are a new group accompanied by rapid urbanization in China. The problem of employment not only is related to their own survival and development, but also directly affects the quality and effectiveness of economic and social development of China. This paper introduces the three-dimensional capital factors of human capital, social capital and psychological capital, comprehensively analyzes the mechanism of their "independent" and "synergistic" influences on the employment of land-expropriated farmers, and constructs a theoretical model of the influences. Based on the survey data of land-expropriated farmers in Daxing district of Beijing, this paper uses the structural equation model to test the theoretical model empirically, and obtains the influence paths and coefficients of three-dimensional capital on the employment of land-expropriated farmers. It is helpful to grasp the key to solve the problem of land-expropriated farmers at the decision-making and implementation levels, and to defuse social risks caused by unemployment of land-expropriated farmers more effectively.
\end{abstract}

\section{Keywords}

Land-Expropriated Farmers (LEFs), Three-Dimensional Capital, Employment, Influencing Mechanism

\section{Introduction}

With the rapid progress of urbanization in China, a large number of rural collective lands have been expropriated, and the scale of land-expropriated farmers (LEFs) has become increasingly large. According to data released by National 
Bureau of Statistics, the urbanization rate of China had reached $58.52 \%$ by the end of 2017 , which was an increase of $1.17 \%$ over the previous year. It is expected to increase to $65 \%$ to $70 \%$ by 2030 [1], and by then, the number of LEFs in China will reach 110 million, of which about 50 million will face different degrees of survival and development problems [2]. The LEFs lose the land they depend on for farming, but without stable employment, they tend to become marginal groups in cities. Although they can get the corresponding money and apartments as the compensation, they are relatively lack of long-term life planning and sustainable development abilities, and they are prone to return to poverty due to improper investments, high consumption in the short term, or problems such as gambling and drug abuse. Therefore, stable employment is the key to solve the problems of LEFs. Compared with other types of social security, employment is an active security, which plays an important role in the sustainable development of LEFs in cities. It is not only related to their survival and development, but also directly affects the quality and effectiveness of economic and social development of China.

The income of LEFs mainly comes from working in the factory or engaging in the rural service industry. As the capacity of rural industry to absorb surplus agricultural labors has declined in recent years, rural service industry has become the main channel for surplus agricultural labors to transfer to non-agricultural industries in China. The service industry is mainly labor-intensive or labor-capital-intensive and many jobs have low skill requirements that can reduce training costs. Moreover, the rural service industry is close to the local reality, which can directly provide local employment opportunities and reduce the cost of finding jobs for farmers. With the development of economy and the improvement of income per capita, people's consumption demand for services will be increasingly large, creating conditions for the service industry to absorb a large number of labors. The development of rural service industry (Agricultural Producer Services, Rural Consumption Services and Rural Public Services) is an important path to increase employment opportunities and increase income of LEFs (Figure 1). However, the rural service industry needs a large number of practical and technical personnel engaged in deep processing of agricultural products, products marketing and circulation services. Lack of technical and skills training, many LEFs are unable to engage in relevant work, and unemployment is the biggest problem facing LEFs.

The employment problem of LEFs has been highly valued by the government and widely concerned by the society. For example, in view of the slow progress of citizenization of rural migrant population and the quality of urbanization needing to be improved in Daxing district of Beijing, the Outline of the 13th Five-Year Plan for National Economic and Social Development of Daxing District and Beijing Economic and Technological Development Zone emphasized to give priority to employment, to promote the employment of key groups, to actively expand employment channels, to achieve the rural migrant population employment and green employment, and to promote the professionalization and 


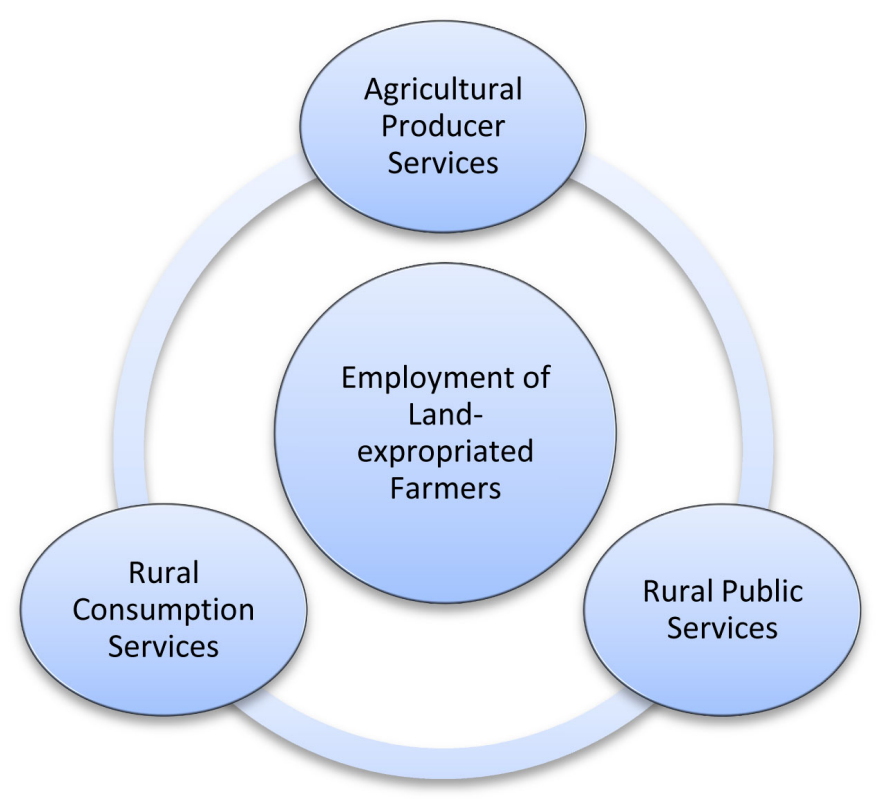

Figure 1. Rural service industry and LEFs employment.

citizenization of farmers. In the current context, the research on the employment of LEFs is helpful to respond to the above concerns, and can provide references for relevant decision-makers.

The main contribution of this paper is to introduce the three-dimensional capital factors of human capital, social capital and psychological capital, comprehensively analyzes the mechanism of their "independent" and "synergistic" influences on the employment of LEFs, and constructs a theoretical model of the influences. Based on the survey data of LEFs in Daxing district of Beijing, this paper uses a structural equation model to test the theoretical model empirically, and obtains the influence paths and coefficients of three-dimensional capital on the employment of LEFs. It is helpful to grasp the key to solve the problems of LEFs at the decision-making and implementation levels, and to defuse social risks caused by unemployment of LEFs more effectively.

\section{Literature Review}

Scholars at home and abroad have been studying the employment of rural migrant workers for years. Typical theories include transformation theory of dual economic structure by W. A. Lewis, Fei-la model by John Fei and Gustav Ranis, the push-pull theory of population transfer by Donald Bogue, labor market segmentation theory by Werner Dollinger and Michael Piore. Based on the differences in national conditions, scholars focus on two topics. The first is the analysis of the employment patterns of rural migrant labor force, such as the mandatory enclosure transfer mode in Britain, the free transfer mode in the United States, and the combination of the leap-forward transfer and rural non-agricultural transfer in Japan [3]. The second is to explore the employment countermeasures of LEFs based on the differences of national conditions through em- 
pirical tests. For example, the United States solved the employment problems of LEFs by actively cultivating and supporting leading industries [4] [5]. The United Kingdom absorbed rural surplus labors by building a service system suitable for agricultural industrialization to develop rural tertiary industry [6], and Japan increased employment opportunities for LEFs by cultivating comprehensive functions of local small cities [7].

The research on LEFs and their employment is mainly carried out from the following three perspectives. The first is the research and evaluation on the resettlements of LEFs. Monetary resettlement is a fixed amount, but it cannot maintain sustainable livelihood [8]. Purchasing insurance for LEFs, and changing one-time land compensation to lifelong guarantee of "land for social security" have problems of unreasonable compensation standards, incomplete land acquisition compensation procedures, and low degree of democratic participation in decision-making of farmers [9]. Under the condition of market economy, the problem of government job placements is that when enterprises dismiss LEFs, the government has no right to interfere [10]. The second is to discuss the difficulties of LEFs employment from the perspectives of relevant system, employment environment and LEFs themselves. For example, Wang (2015) studied the imperfection of land expropriation system, social security system and training system, which restricted the employment of LEFs [11]. Zhou (2015) found that the weak abilities of intermediary organizations and the social exclusion become obstacles to the employment of LEFs [12]. Wang et al. (2017) found that LEFs face severe employment situation due to their low knowledge level and skills level [13]. The third is to analyze the employment paths and necessary assistances of LEFs in the process of urbanization [14] [15].

On the whole, scholars have demonstrated the employment problems of LEFs from multiple perspectives. However, in terms of the measures to solve the problem, there are not enough innovations and breakthroughs in the research perspective combining economic attributes and social attributes. In the selection of variables that affect the employment of LEFs, multidimensional variables are rarely used, and the research is not comprehensive and complete.

Combining three-dimensional capital with employment, the main discipline basis is labor economics, sociology and psychology. The existed researches from the perspective of three-dimensional capital mainly include three aspects. Firstly, it is applied to the research of poverty alleviation and anti-poverty mechanism [16]. Secondly, it is applied to the study of urban integration behaviors of rural migrant workers [17]. Thirdly, it is applied to the research on employment assistances, and the objects of assistances include knowledge talents like college students [18]. Although it has been extended to LEFs, a vulnerable group in non-agricultural employment [19], the relevant literature is very limited and the research lacks completeness. It is not only a weak point but also a growth point to study the influences of three-dimensional capital on the employment of LEFs and then to carry out employment assistances. 


\section{The Independent Influences of Three-Dimensional Capital Factors on the Employment of LEFs}

1) The Influences of Human Capital. Human capital is the capital embodied in human beings, and it is the condensation of producers' expenditures on general education and vocational training and their opportunity costs of receiving education. It is manifested as the total stock of production knowledge, management skills and physical constitutions contained in human beings. There is a functional relationship between the employment and the human capital. Many scholars conduct researches on LEFs employment from the perspective of human capital. They believe that education and training are important aspects to promote the accumulation of human capital of LEFs and play an important role in LEFs employment [20], and are also important influencing factors for the transformation of farmers from low-level urban integration to high-level urban integration [21]. However, the human capital accumulation of LEFs is a low level, and they are in a weak position in the employment competition due to the constraints of resources, policies, views and values, education and other factors. Therefore, the following hypothesis is established:

H1: The human capital accumulation of LEFs plays a positive role in their employment.

2) The Influences of Social Capital. Social capital is essentially a specific social network formed by human interactions and its potential social resources. It is reflected in the social network relations and becomes a real capital only when it is used and mobilized by the doers. By nature, the social capital can be divided into the homogeneous social capital (strong-relationship) and the heterogeneous social capital (weak-relationship). The homogeneous social capital can be subdivided into family, kindred, local and emotional social capital. The heterogeneous social capital is often constructed on the basis of modern legal factors. There are workmates type, classmates type, comrade-in-arms type and interests type social capital, and there are also legal social capital based on a certain public benefits purpose or industrial benefits purpose, such as social intermediary organizations and various industrial associations. Zhao (2016) found that social capital was one of the dominant factors affecting the employment of rural migrant labor force [22]. Lin et al. (2010) found that it could improve the efficiency of individual job hunting, and had the characteristics of low information acquisition costs, high information credibility and easy to form "group advantages" [23]. The social capital stock of LEFs is generally low and the homogeneous social capital is the main way for them to obtain employment information. The homogenous social capital (strong-relationship) is characterized by easy communication, high stability and strong willingness, which can improve the employment possibility of LEFs. However, Ci (2011) found that it was the weak-relationship rather than the strong-relationship that was more conducive to individuals to obtain higher quality job information and find a better job [24]. The richer the extended heterogeneous social capital (weak-relationship), the more conducive it is to the em- 
ployment and career development of LEFs. Social capital is reflected in reciprocity norms, and the development of rural service industry requires the input of resources, and social capital can expand the source of funds for it. The key to the sustainable interactions between social capital and rural service industry lies in the win-win situation. The sustainability and benign development of rural service industry are bound to affect its job absorption capacity and expansion of employment space for LEFs. Therefore, the following hypothesis is established:

H2: The social capital accumulation of LEFs plays a positive role in their employment.

3) The Influences of Psychological Capital. Psychological capital is a core element that transcends human capital and social capital. It is the psychological resource to promote the personal growth and performance improvements, and is the key to win in human resources [25]. Based on a positive psychological paradigm, it embodies optimism, confidence, hope and resilience for the future, as well as self-management ability in the face of adversity. Psychological capital is nonspecific and can be acquired and developed through training. At the individual level, psychological capital is a positive psychological resource to promote self-growth and development. At the organizational level, psychological capital wins competitive advantages for the organization by improving employee performance [26]. Ke et al. (2010) found that psychological capital had the highest positive correlation with performance and work attitude, followed by social capital and human capital [27]. However, LEFs generally have complex psychology and mentality, and encounter various psychological barriers and perplexities in the process of urbanization. Psychological capital accumulation can enhance LEFs' anti-frustration ability in the process of employment, can strengthen self-motivation to face occupational discrimination optimistically, through unremitting efforts to find jobs, and maintain good occupational stability and development. Therefore, the following hypothesis is established:

H3: The psychological capital accumulation of LEFs plays a positive role in their employment.

Human capital, social capital and psychological capital constitute the valuable human resource system of LEFs. Furthermore, the sustainable interactive developments of social capital and rural service industry promote the expansion of LEFs employment space and the increase of employment opportunities. The three-dimensional capital factors play a crucial role in the employment of LEFs.

\section{The Synergistic Influences of Three-Dimensional Capital Factors on the Employment of LEFs}

The core idea of synergy is that if each subsystem in a system can cooperate well, multiple forces can collectively contribute to the total force, thus forming new functions beyond the original sum of their respective functions. Three-dimensional capital does not exist in isolation on each LEF. They interact with each other and play a synergistic role in the non-agricultural employment (Figure 2). 

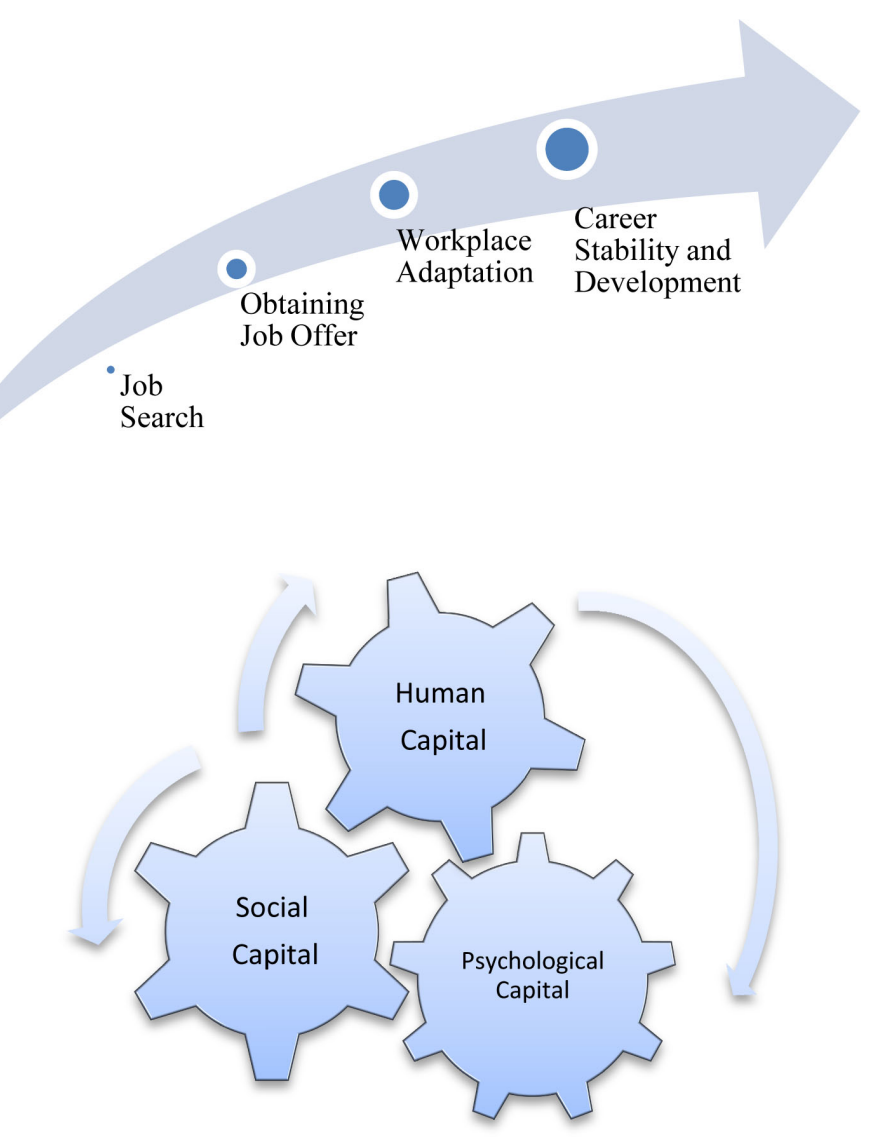

Figure 2. The synergistic influences of three-dimensional capital on the employment of LEFs.

\section{1) The Synergistic Influences of Human Capital and Social Capital}

The more abundant human capital individuals have, the more they can expand their own social network breadth and enhance the strength of the network, thus enriching the individual's social capital. The difference of human capital of LEFs affects their ability to construct social relation network. The higher the level of human capital is, the higher the occupational level is, and the more social resources it carries. This will continuously expand the personal social network, break through the original social model based on homogeneous social capital, and enable more heterogeneous social capital to accumulate. Finally, individuals can enjoy the exchange of resources in a broader social network. The accumulation of social capital of LEFs, especially heterogeneous social capital, can increase the social supports of individuals, expand the information channels for individuals to acquire knowledge and technology, and thus improve individual human capital. The human capital of LEFs exists on the basis of social capital, which can save a lot of time and transaction costs only if it is effectively transmitted in the social network, and finally, reduce the risk of unemployment and realize its capital value. Hence, the following hypotheses are established:

H4: The human capital of LEFs plays a positive role in their social capital accumulation. 
H5: The social capital of LEFs plays a positive role in their human capital accumulation.

2) The Synergistic Influences of Social Capital and Psychological Capital

The LEFs generally lack heterogeneous social capital, namely, weak-relationship social capital. The weak-relationship promotes the information flow between different groups, disseminates information that people are unlikely to see, and plays a positive role in obtaining employment information of LEFs. Studies have shown that weak-relationship is most likely to provide friends with information that would otherwise be difficult for them to access. Ci (2011) found that a weak-relationship increased the likelihood of information sharing by nearly 10 times, while a strong-relationship increased the likelihood by only 6 times [24]. For LEFs, more strong-relationship and weak-relationship can strengthen their social capital and improve their self-confidence in employment. Positive psychological capital plays a positive role in promoting the accumulation of social capital, especially heterogeneous social capital. LEFs with higher self-efficacy will actively and consciously expand their interpersonal network and social space. Meanwhile, LEFs who are optimistic, confident and resilient have strong interpersonal attraction, which is more conducive to expanding social radius, accumulating more heterogeneous social capital and winning more employment opportunities. Therefore, the following hypotheses are established:

H6: The social capital of LEFs plays a positive role in their psychological capital accumulation.

H7: The psychological capital of LEFs plays a positive role in their social capital accumulation.

3) The Synergistic Influences of Human Capital and Psychological Capital

Firstly, the accumulation of human capital has a positive impact on the psychological capital accumulation of LEFs. The higher the human capital level of LEFs is, the stronger the employment opportunity perception and employment ability is, and the more likely they are to find a job. This will increase their self-confidence and firm their belief that they can achieve their dreams through hard work. Even in the face of setbacks and difficulties, they can still maintain a positive attitude towards employment with optimism and tenacity, and constantly improve their anti-frustration ability in adversity. Secondly, the psychological capital of LEFs has a correlated impact on their human capital accumulation. The more positive psychological components LEFs have, the stronger their self-efficacy is, and the more willing they are to adapt to new fields, accept new skills and new ideas, and show more flexibility and creativity in the process of career search. The higher the level of psychological capital of LEFs, the more able they are to stimulate their own motivation of achievement, thus consciously strengthening the improvement of knowledge, skills and experience. On the contrary, the lower the level of human capital is, the more likely for LEFs to be frustrated in the process of employment, and also prone to produce a negative psychological state. The more negative psychological components of LEFs, the more pessimistic they are about their career and future, the more closed and re- 
jected they are to the outside world, and the more passive they are to participate in employment training. This negative psychological state is bound to restrain the accumulation of human capital and the display of its effectiveness. If not properly handled, it may lead to many negative misconducts and bring about a series of social problems. Therefore, the following hypotheses are established:

H8: The human capital of LEFs plays a positive role in their psychological capital accumulation.

H9: The psychological capital of LEFs plays a positive role in their human capital accumulation.

Theoretical analysis shows that human capital, social capital and psychological capital play a role in promoting the employment of LEFs. Meanwhile, three-dimensional capital factors play a synergistic role in the process of job search, obtaining job offer, workplace adaptation, career stability and development (Figure 2).

\section{Empirical Analysis}

Daxing district of Beijing is one of the 2nd batches of national comprehensive pilot areas for new urbanization, and the integration of migrant workers into cities and towns is one of the pilot areas. According to Beijing municipal development plan, Daxing district is relying on the new airport to build an internationally leading airport economic zone, creating an international high-end industrial park, on the basis of Beijing economic and technological development zone, and taking the pilot project of collective profit-oriented construction land as a breakthrough to build the pilot zone of deepening reform. The problem of employment of LEFs brought by the rapid development of this area is unavoidable and has strong representativeness and demonstration effects. In order to further test the validity of the core assumptions and the measurement indexes, the research group used the survey data of the employment of LEFs in Daxing district of Beijing collected in April 2017 to test the theoretical model.

\section{1) Construction of Econometric Model}

Although scholars have conducted various researches on the employment of LEFs, most of them focus on theoretical researches and adopt more qualitative methods, making it difficult to accurately analyze the significant effects of various factors on employment and relevant issues. Structural equation model (SEM) can be used to estimate and verify abstract concepts. Anderson et al. (1988) found that SEM could be applied to estimate the parameters of potential variable or complex independent variable and dependent variable in the prediction model, which could not only help analyze the measurement error, but also analyze the structural relationship between potential variables, which was an important method to deal with the problem of multiple variables (including potential variables) in social science research [28]. This study belongs to the category of social science research, including many variables, which is suitable to use SEM for measurement. 
Theoretical analysis shows that the more abundant the human capital, social capital and psychological capital the LEFs have, the stronger the employment competitiveness and more employment opportunities they have. According to relevant studies on the employment of LEFs, combined with characteristics of LEFs and questionnaire survey, observed variables of human capital, social capital, psychological capital and employment are extracted as shown in Table 1. Furthermore, according to the hypotheses, a theoretical model of LEFs employment can be constructed (Figure 3).

\section{2) Data Description}

The data are from a questionnaire survey of 33 land-expropriated villages in Daxing district of Beijing (some or all of the productive land has been expropriated). 40 LEFs were randomly selected from each village as survey samples, and a combination of questionnaire and interview was adopted to conduct the survey. A total of 1321 questionnaires were distributed, of which 1105 were effectively collected, with an effective recovery rate of $83.6 \%$ and 25 interview records were obtained. Among the valid samples, 453 men (41\%) and 652 women (59\%) were included. Those born after 1980 accounted for $34.9 \%$ of the

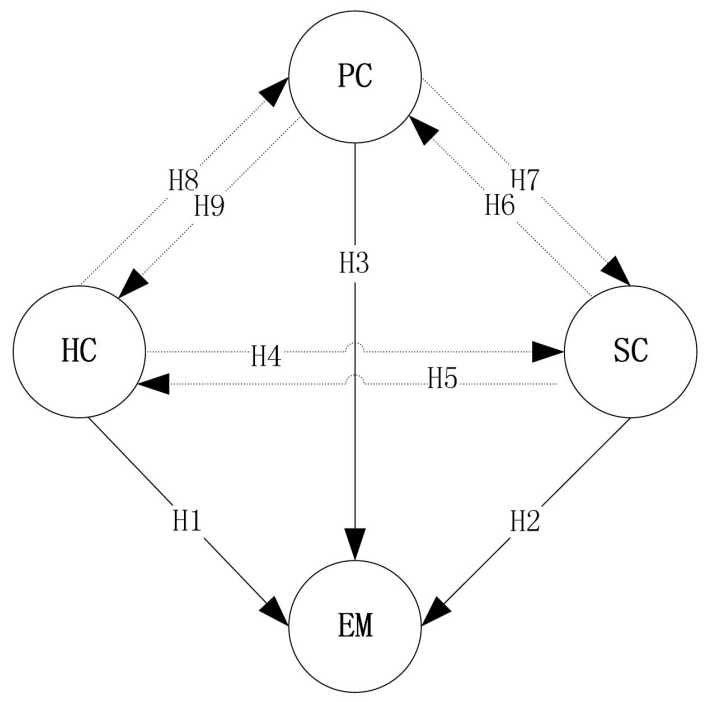

Figure 3. Theoretical model of three-dimensional capital influencing LEFs employment.

Table 1. Three-dimensional capital influencing LEFs employment model variables.

\begin{tabular}{cl}
\hline Latent Variable & \multicolumn{1}{c}{ Observed Variable } \\
\hline Human Capital (HC) & $\begin{array}{l}\text { Education }\left(\mathrm{X}_{1}\right) \text {, skills }\left(\mathrm{X}_{2}\right) \text {, training }\left(\mathrm{X}_{3}\right), \\
\text { continuous learning }\left(\mathrm{X}_{4}\right)\end{array}$ \\
Social Capital (SC) & $\begin{array}{l}\text { Referee }\left(\mathrm{X}_{5}\right) \text {, information channel }\left(\mathrm{X}_{6}\right), \\
\text { convenient consulting }\left(\mathrm{X}_{7}\right) \text {, credit aid }\left(\mathrm{X}_{8}\right)\end{array}$ \\
Psychological Capital (PC) & $\begin{array}{l}\text { Self-confidence }\left(\mathrm{X}_{9}\right) \text {, optimistic and positive }\left(\mathrm{X}_{10}\right), \\
\text { occupation expectation }\left(\mathrm{X}_{11}\right), \text { resilience }\left(\mathrm{X}_{12}\right)\end{array}$ \\
Employment $(\mathrm{EM})$ & Obtaining job offer $(\mathrm{Y})$
\end{tabular}


total sample, and the older generation farmers accounted for $65.1 \%$. The number of employed persons was 497 , accounting for $45 \%$ of the total sample (269 men, accounting for 54\%; 228 women, accounting for 46\%). The distribution of employed persons was: construction $14.08 \%$ (70 persons), manufacturing $13.08 \%$ (65 persons), wholesale and retail 19.11\% (95 persons), residential services and other services $16.50 \%$ ( 82 persons), accommodation and catering $15.29 \%$ (76 persons), transportation, warehousing and postal service $21.93 \%$ (109 persons). The 5-point Likert Scale was used to measure the items in this questionnaire. The measuring scale was 5 points for very large impact, 4 points for relatively large impact, 3 points for general impact, 2 points for relatively small impact, and 1 point for very small impact.

\section{3) Questionnaire Test}

Reliability analysis can be used to test whether the measurement results reflected the real characteristics of the respondents' stability and consistency. The higher the reliability of the scale is, the smaller the standard error is. Reliability coefficient above 0.7 is acceptable, and above 0.8 means high internal consistency.

Firstly, SPSS18.0 software was used to test the independence of the questionnaire data, and the questions with low identification degree (Employment Expectation) were eliminated. The Cronbach coefficient was further used for reliability analysis, and the Cronbach's Alpha coefficient of the scale in the questionnaire was 0.916 . This indicated that the questionnaire had good internal consistency and the evaluation results had high reliability. Secondly, the validity of the questionnaire was analyzed. Six experts were invited to evaluate the content and structure of the questionnaire, and the expert identification rate was $95.12 \%$, indicating that the validity of the questionnaire was high.

\section{4) Hypothesis Test}

a) Fitting Degree Analysis

Table 2 reflects the degree of fitting between structural equation model and survey data. The chi-square value of the model is 871.339 , the degree of freedom is 403 , and the statistical significance $P$ of chi-square test is less than 0.001. Chi-square value and degree of freedom ratio are 2.162 , less than 3 , which can truly reflect the survey data. The other two absolute fitting indexes GFI is 0.921 ,

Table 2. Fitting degree indices of the evaluation model.

\begin{tabular}{|c|c|c|c|c|c|c|c|c|c|}
\hline \multirow{2}{*}{ Model } & \multicolumn{4}{|c|}{ Absolute Indices } & \multicolumn{3}{|c|}{ Relative Indices } & \multicolumn{2}{|c|}{ Information Indices } \\
\hline & $\mathrm{X} 2$ & Df & GFI & RMSEA & CFI & IFI & NFI & AIC & BIC \\
\hline Ref. Value & $\begin{array}{c}\text { The smaller, } \\
\text { the better } \mathrm{P}<0.05\end{array}$ & $\mathrm{X} 2 / \mathrm{Df}<3$ & $>0.90$ & $<0.05$ & $>0.90$ & $>0.90$ & $>0.90$ & $\begin{array}{l}\text { The smaller, } \\
\text { the better }\end{array}$ & $\begin{array}{l}\text { The smaller, } \\
\text { the better }\end{array}$ \\
\hline 1 & $871.339^{* * *}$ & 403 & 0.921 & 0.043 & 0.909 & 0.907 & 0.915 & 937.625 & 1001.824 \\
\hline
\end{tabular}

Note: a) ${ }^{*} \mathrm{P}<0.05,{ }^{* *} \mathrm{P}<0.01,{ }^{* *} \mathrm{P}<0.001$; In the structural equation model, the significance level reaches 0.05 , which means there is significant difference between the hypothesis model and the observed data. RMSEA is the root mean square error of approximation and value of 0.05 (or 0.08 ) or below indicate good model fitting. GFI is the absolute fitting index. Value of 0.90 and above indicate good model fitting. b) CFI, IFI and NFI are relative fitting indices. Value of 0.90 and above indicate good model fitting. c) AIC and BIC are information indices, and the smaller they are, the simpler and more efficient the model will be. 
greater than 0.90 , RMSEA is 0.043 , less than 0.05 , indicating that the model is basically fitted. Relative fitting indexes CFI is 0.909 , IFI is 0.907 , and NFI is 0.915 , all of which are greater than 0.90 , indicating a good model fitting. The information indexes AIC and BIC are 937.625 and 1001.824 respectively. Meanwhile, the measurement error of each observation variable is within the allowable range in the measurement model. On the whole, the model and data have a good fit, which can effectively reflect the interaction between variables and test the hypotheses.

b) Model Test and Result Analysis

Structural equation model analysis was carried out with AMOS7.0 software. After a series of steps as normality test, outliers test and parameter correction, the modified structural equation model (Figure 4) and the effects of three-dimensional capital latent variables on employment (Table 3 ) are obtained.

In Figure 4, the arrows represent the direct influences between variables, and the values represent the path coefficients, i.e. the direct influence of one variable on another. The larger the value is, the greater the influence of one variable on the other is. The specific analysis results are as follows: firstly, the modified

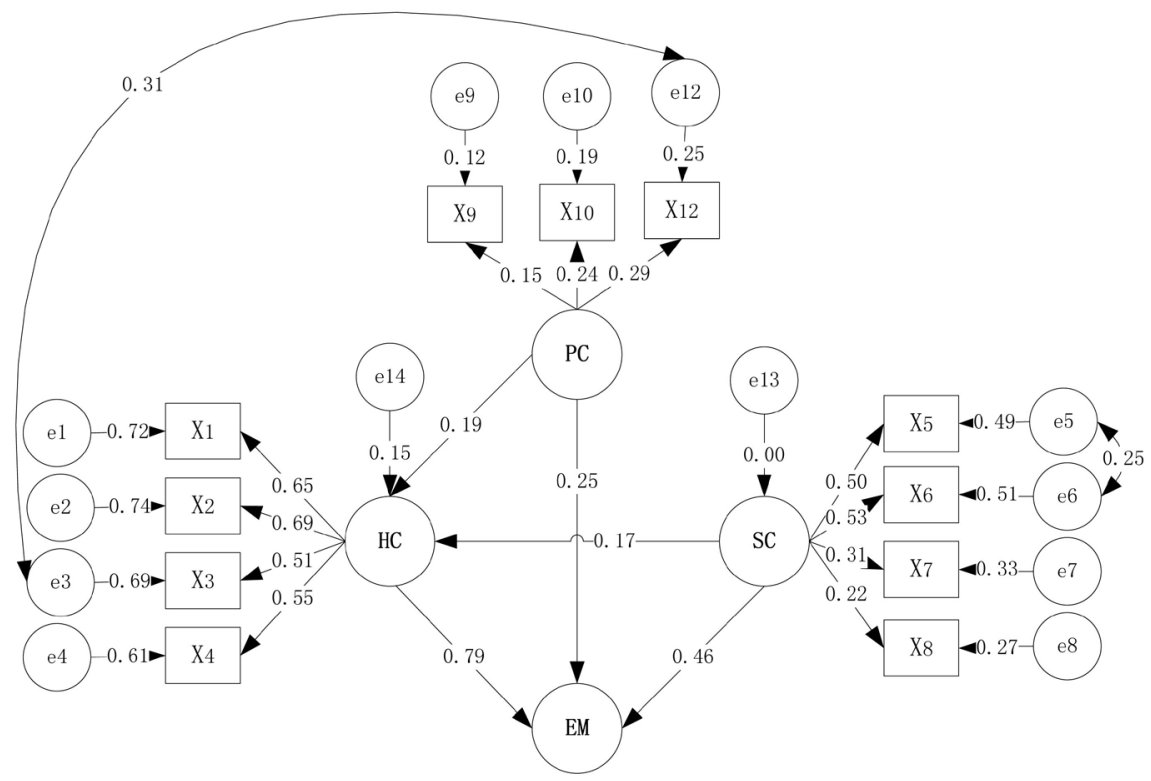

Figure 4. Measurement model path coefficient. Note: The path coefficient is the standardized value, $\mathrm{P}<0.05$.

Table 3. Effects of model variables on employment.

\begin{tabular}{cccc}
\hline & The Direct Effect & \multicolumn{2}{c}{ The Indirect Effect on Employment } \\
\cline { 3 - 4 } Latent Variables & on Employment & $\begin{array}{c}\text { Social Capital's Influence } \\
\text { on Human Capital }\end{array}$ & $\begin{array}{c}\text { Psychological Capital's } \\
\text { Influence on Human Capital }\end{array}$ \\
\hline Human Capital & 0.79 & 0.00 & 0.00 \\
Social Capital & 0.46 & 0.17 & 0.00 \\
Psychological Capital & 0.25 & 0.00 & 0.19 \\
\hline
\end{tabular}


model eliminates the observation variable with a small loading coefficient (e11Occupation Expectation) and 4 paths with insignificant loading coefficients. They are human capital's positive influence on social capital (H4), social capital's positive influence on psychological capital (H6), psychological capital's positive influence on social capital (H7), and human capital's positive influence on psychological capital (H8). That is, the above hypotheses are not valid. Meanwhile, two Common paths e5 - e6 and e3 - e12 are added. Secondly, at the significance level of $5 \%$, the human capital has a positive impact on the employment of LEFs, with an impact coefficient of 0.79. Hypothesis 1 is valid. The influence coefficients of the four observable variables on human capital are $0.65,0.69,0.51$ and 0.55 respectively. This shows that LEFs really feel the important influences of human capital on the employment. Thirdly, the social capital has a positive impact on the employment of LEFs, with an impact coefficient of 0.46. Hypothesis 2 is valid. The influence coefficients of the four observed variables on social capital are $0.50,0.53,0.31$ and 0.22 respectively. Fourthly, the psychological capital has a positive impact on the employment of LEFs, and the impact coefficient is 0.25 . Hypothesis 3 is valid. The influence coefficients of confidence, optimism, and resilience on psychological capital are $0.15,0.24$ and 0.29 respectively. Fifthly, the social capital of LEFs has a positive impact on human capital, and the impact coefficient is 0.17 . Hypothesis 5 is supported. Sixthly, the psychological capital of LEFs has a positive impact on human capital, and the impact coefficient is 0.19 . Hypothesis 9 is supported. Therefore, it is valid to assume that the human capital, social capital and psychological capital have positive effects on the employment, and that the social capital and psychological capital have positive effects on the human capital.

In Table 3, the human capital, social capital and psychological capital have a positive and direct impact on the employment of LEFs, and their standardized path coefficients are 0.79, 0.46 and 0.25 respectively. Among them, the human capital has the biggest impact. Every one standard deviation increase of human capital directly causes 0.79 standard deviation increase of the employment of LEFs. Although the direct impact of social capital and psychological capital on employment is lower than that of human capital, there are indirect impacts for them two. The standardized path coefficients of the social capital and psychological capital on human capital are 0.17 and 0.19 respectively, that is, both of them indirectly affect the employment through positive influences on human capital.

\section{Conclusions}

At present, there are no researches on the employment of LEFs from the perspective of three-dimensional capital with the method of structural equation model. This paper constructs a comprehensive theoretical model of the influence of three-dimensional capital on the employment of LEFs. By using the survey data of LEFs in Daxing district of Beijing, and using the structural equation 
model to carry out an empirical test of the theoretical model, the influence paths and effects of three-dimensional capital on the employment of LEFs are obtained. The specific research conclusions are as follows:

From the perspective of direct impact paths, the human capital, social capital and psychological capital directly determine whether LEFs can be employed. From the perspective of the size of impact effects, the largest is the human capital. Education, skills, training and continuous learning constitute the most valuable human resources system of LEFs, which is the basis of the employment of LEFs. The government should make great efforts to increase the investment in education and training of LEFs and improve their human capital so as to effectively meet the social demand for LEFs. The direct impact effects of the social capital are ranked the second place. To promote the employment of LEFs, it is necessary to reconstruct their social capital. In order to increase their employment channels and opportunities, LEFs should gradually shift from the traditional homogeneous social capital model to the diversified and heterogeneous modern social capital model. The direct impact effects of psychological capital are ranked the third place. Based on the principle of gradual and orderly developments, the positive psychological capital of LEFs should be developed, so that they can have a process of pressure relief and adaptation, constantly enhance their endogenous strength to get out of the employment dilemma, and finally promote them to achieve the employment goal at the right time.

From the perspective of indirect influence paths, the social capital and psychological capital indirectly affect the employment of LEFs by affecting the human capital. The indirect effects of the social capital on the employment of LEFs are stronger than that of the psychological capital. LEFs should enhance the accumulation of diverse and heterogeneous social capital, and expand the information channels to acquire knowledge and technology by increasing the social supports of individuals, so as to improve individual human capital. It is necessary to fully realize that the human capital of LEFs is dependent on social capital and can only be effectively transmitted in the social network to realize its human capital value and reduce the risk of unemployment. Secondly, the positive or negative psychological state of LEFs affects their initiative in learning and training. This inhibits the accumulation of human capital, affects employment, and even causes negative anomic behaviors. Therefore, the government should construct a mechanism to relieve the pressure of LEFs by constantly improving the social security, and at the same time help them to participate in vocational training during unemployment, so as to better realize re-employment. The mass media should actively publicize the entrepreneurial behaviors and achievements of LEFs and guide those with good conditions and positive attitudes to start their own businesses. Labor departments and enterprises should give more care and help to LEFs, carry out psychological counseling and ideological work, and create a sense of organizational supports.

The problem of LEFs is an emerging problem in the process of development 
and must be solved in the development. Therefore, we should not only strengthen employment and social security on the whole to promote the comprehensive, coordinated and sustainable developments of the economy and the society, but also promote the self-development of LEFs from the perspective of three-dimensional capital.

\section{Supporting Projects}

1) The Employment Supports for Land-expropriated Farmers of Daxing District in Beijing from the Perspective of Three-dimensional Capital, Beijing Social Science Foundation Research Base Project (16JDSRC008). 2) The Employment Effects of Producer Services in Beijing, Beijing Municipal Education Commission Project (SM201610017001). 3) The Employment Supports for Land-expropriated Farmers of Daxing District in Beijing-from the Perspective of Three-dimensional Capital, Beijing URT Project (2019J00166).

\section{Conflicts of Interest}

The authors declare no conflicts of interest regarding the publication of this paper.

\section{References}

[1] Li, G.L. (2014) Employment Ability Development of Land-Expropriated Farmers from the Perspective of Sustainable Livelihood. Development Research, 1, 27-30.

[2] Chen, H. and Chen, X.C. (2013) Analysis of Employment Differentiation and Characteristics of Land-Expropriated Farmers in the Urbanization Process Based on the Survey Data of 858 Households in the Yangtze River Delta. Survey World, 7, 34-40.

[3] Zhang, J. and Jiang, G. (2010) Experience and Inspiration of Foreign Urbanization and Rural Labor Transfer. Financial Economy. Theory Edition, 11, 27-29.

[4] Finch, J.H. (2010) The Re-Employment Experiences of Former Aerospace Employees within a Local Economy. Regional Studies, 32, 421-433. https://doi.org/10.1080/00343409850116826

[5] Grün, C., Hauser, W. and Rhein, T. (2010) Is Any Job Better than No Job? Life Satisfaction and Re-Employment. Journal of Labor Research, 31, 285-306. https://doi.org/10.1007/s12122-010-9093-2

[6] Imbens, G.W. and Lynch, L.M. (2006) Re-Employment Probabilities over the Business Cycle. Portuguese Economic Journal, 5, 111-134. https://doi.org/10.1007/s10258-006-0006-5

[7] Alba, A., Arranz, J.M. and Muoz-Bullón, F. (2012) Re-Employment Probabilities of Unemployment Benefit Recipients. Applied Economics, 44, 3645-3664. https://doi.org/10.1080/00036846.2011.579067

[8] Zhai, N. and Xiang, G.Q. (2012) Constraints on Employment of Land-Expropriated Farmers in the Process of Urbanization and Policy Support. Chinese Public Administration, 2, 50-53.

[9] Hou, Z.J. (2011) Theory and Practice of "Land for Social Security". Legal System and Society, 4, 181-182.

[10] Liu, H. and Liu, J. (2009) Research on Resettlement Mode Selection of Land-Ex- 
propriated Farmers. Commercial Research, 10, 11-15.

[11] Wang, X.G. (2015) International Reference of Land Compensation and Employment Support for Land-Expropriated Farmers from the Perspective of Population Urbanization. Journal of Agro-Forestry Economics and Management, 6, 644-652.

[12] Zhou, B.F. (2015) Analysis on the Rights and Interests of Land-Expropriated Farmers from the Perspective of Social Exclusion. Issues in Agricultural Economy, 4, 59-65.

[13] Wang, Y., Chen, J. and Wang, Q. (2017) Can Human Capital and Social Capital Improve the Employment Level of Land-Expropriated Farmers Based on the Survey Data of Continuous Tracking in Beijing. Economic Theory and Business Management, 4, 42-59.

[14] Xie, J. (2012) Occupational Transformation and Supporting Mechanism of Land-expropriated Farmers. Social Sciences Academic Press, Beijing.

[15] Shi, P. and Sun, L. (2017) Research on Employment Pattern of Land-Lost Farmers in Ethnic Minority Areas Based on the Background of New Urbanization Construction. Urban Studies, 1, 154-158.

[16] Huang, C. and Shen, Y. (2013) Thinking on Improving China's New Rural Poverty Alleviation and Development Strategy and Anti-Poverty Mechanism under Three-Dimensional Capital Coordination. Gansu Social Sciences, 3, 139-142.

[17] Zhang, H. (2013) The Endogenous Mechanism Innovation of the Social Integration of the New Generation of Migrant Workers-The Synergistic Effect of Human Capital, Social Capital and Psychological Capital. Research of Agricultural Modernization, 4, 412-416.

[18] Yang, H. and Liu H. (2013) Three-Dimensional Capital and College Students' Employment. Journal of Hebei University. Philosophy and Social Sciences, 6, 117-120.

[19] Jia, H. (2017) Research on Non-Agricultural Employment Support Mechanism of Land-Expropriated Farmers from the Perspective of Three-Dimensional Capital Based on a Survey of Daxing District, Beijing. Comparative Economic and Social Systems, 5, 92-104.

[20] Tong, X., Jin, H. and Shi, Q. (2012) Urban Integration of Migrant Workers: An Empirical Study from the Perspective of Human Capital and Social Capital. Economic Survey, 5, 33-37.

[21] Lu, H., Zheng, Y. and Qian, W. (2016) Behavior Analysis of Migrant Workers' Integration into Cities Based on Survey Data of 1632 Migrant Workers. Journal of Agro-Technical Economics, 1, 26-36.

[22] Zhao, M.C. (2016) A Case Study on the Impact of Social Capital on the Employment Quality of New Generation Migrant Workers in SZ City. Population and Development, 2, 48-55.

[23] Lin, S.L. and Zhang, L.H. (2010) The Relationship Between Human Capital and Migrant Workers' Employment Search Time Based on the Questionnaire Survey in Rural Areas of Fujian Province. Rural economy, 6, 101-104.

[24] Ci, Y.P. (2011) Granovetter's Theory of Weak Ties. Management Scientist. Practical Edition, 6, 63-71.

[25] Luthans, F., Luthans, K.W. and Luthans, B.C. (2004) Positive Psychological Capital: Beyond Human and Social Capital. Business Horizons, 47, 45-50. https://doi.org/10.1016/j.bushor.2003.11.007

[26] Luthans, F., Youssef, C.M. and Avolio, B.J. (2007) Psychological Capital: Developing the Human Competitive Edge. Oxford University Press, Oxford. 
[27] Ke, J., Sun, J., Shi, J. and Gu, Q. (2010) Influence of Human Capital, Social Capital and Psychological Capital on Work Performance, Total Effect Difference and Regulating Factors. Journal of Industrial Engineering and Engineering Management, 4, 29-35.

[28] Anderson, J.C., Gerbing, David W. (1988) Structural Equation Modeling in Practice: A Review and Recommended Two-Step Approach. Psychological Bulletin, 103, 411-423. https://doi.org/10.1037/0033-2909.103.3.411 